\title{
Mild and Efficient Silylcyanation of Aldehydes Catalyzed by Alkali Metal Fluorides
}

\author{
Sung Soo Kim, Jun Tae Lee, and Sang Hyuck Lee \\ Department of Chemistry, Inha University, Incheon 402-751, Korea. *E-mail: sungsoo@inha.ac.kr \\ Received March 3, 2005
}

Key Words : Alkali metal fluorides, Aldehydes, TMSCN, Addition

\begin{abstract}
Cyanohydrins ${ }^{1}$ occupy very important role in organic synthesis due to its synthetic versatility that can easily be converted into various polyfuntionalized building blocks, including $\alpha$-hydroxy compounds and $\beta$-amino alcohols. Diorganotin dichloride ${ }^{2}$ catalyzes the addition of trimethylsilyl cyanide (TMSCN) to various ketones and aldehydes. A very similar addition to the carbonyl compounds ${ }^{3}$ was also found to be catalyzed by copper(II) triflate. Silylcyanation of aromatic ketones is strongly promoted in organic solutions of lithium perchlorate and lithium tetrafluoroborate. Layered zirconium hydrogen phosphate exchanged with potassium ion $^{5}$ was found to be an efficient catalyst for silylcyanation of carbonyl compounds. Indium tribromide $\left(\mathrm{InBr}_{3}\right)^{6}$ is a very effective catalyst for the addition of TMSCN to functionalized ketones. Silylylcyanations of ketones ${ }^{7}$ were also initiated by N-Oxides/Ti(iPro $)_{4}$ as the catalysts. Chiral salentitanium complex ${ }^{8}$ proved to be an effective catalyst for the enantioselective silylcyanation of aldehydes. A new bifunc-
\end{abstract} tional asymmetric catalyst ${ }^{9}$ was devised for the silylcyanation of various aldehydes. $\mathrm{It}^{9}$ is assumed that aluminium would work as a Lewis acid to activate the carbonyl group and the oxygen atom of the phosphine oxide would work as a Lewis base to activate the silylated nucleophiles. The asymmetric addition of TMSCN to aldehydes ${ }^{10}$ can be catalyzed by chiral (salen) titanium complexes. Chiral (salen) VO catalyst ${ }^{11}$ is found to be more enantioselective than the previous titanium-based systems ${ }^{10}$ for the silylcyanation. Various metal salts ${ }^{2-11}$ have been employed as the catalyst for the silylcyanation of carbonyl compounds. Potassium fluoride $(\mathrm{KF})^{12}$ has been the catalyst for silylcyanation of 2-octanone with the yield of only $20 \%$. We wish to herein report the example of silylcyanation of aldehydes by using various alkali metal fluorides.

Benzaldehyde reacts with TMSCN in $\mathrm{CH}_{3} \mathrm{CN}$ under the influence of various catalysts ( $\mathrm{LiF}, \mathrm{NaF}, \mathrm{KF}$, and $\mathrm{RbF}$ ) to give the trimethylsilyl ethers. The result indicates that KF and $\mathrm{RbF}$ can be the prominent catalyst for the silylcyanation. Both catalysts require only $2 \mathrm{~mol} \%$ content for the $100 \%$ conversion of benzaldehyde within 20 min (Table 1). However, $\mathrm{RbF}$ gives a little lower yield of silyl ethers (yield: 93\%). KF was chosen as the best catalyst for the silylcyanation of various aldehydes (Table 2). Variously substituted benzaldehydes (enrtries 1-6) add to TMSCN to give trimethylsilyl ethers over $95 \%$ yield. This indicates that substituent effect is not serious matter for the reactions. Allylic aldehydes (entries 7 and 8) undergo smooth silyl-
Table 1. Trimethylsilylcyanation of Benzaldehyde with Various Catalysts

\begin{tabular}{cccc}
\hline Entry & Substrate & Catalyst & Conversion $(\%)^{a, b}$ \\
\hline 1 & $\mathrm{LiF}$ & 32 \\
2 & $\mathrm{NaF}$ & 81 \\
3 & $\mathrm{KF}$ & 100 \\
4 & $\mathrm{RbF}$ & 100 \\
& & & \\
\end{tabular}

${ }^{a}$ Conversion was measured without separation of reaction mixture. The quantities of the reagents are as follows, $\mathrm{C}_{6} \mathrm{H}_{5} \mathrm{CHO}(10 \mathrm{mmol})$, TMSCN $(15 \mathrm{mmol}), \mathrm{MF}(2 \mathrm{~mol} \%), \mathrm{CH}_{3} \mathrm{CN}(10 \mathrm{~mL}) .{ }^{b}$ Solvent is $\mathrm{CH}_{3} \mathrm{CN}$ and the reaction time is within 20 min.

cyanation with excellent yield. Cyclic aldehydes (entries 9 and 10) can be easily transformed into the silylethers without difficulty. 2-Furaldehyde, a heterocyclic aldehyde (entry 11) gives corresponding silylether with the high yield. This result indicates that KF can selectively activate the carbonyl function keeping the furan ring intact. The order of catalytic activity of $\mathrm{RbF}, \mathrm{KF}>\mathrm{NaF}>\mathrm{LiF}$ could be ascribed to degree of ionization of the salts into the metal cation and fluoride anion. The yield is even better than the silylcyanation catalyzed by zirconium complex. ${ }^{13}$ The result is indicated in the Table 2. The possible mechanism for the reaction is as follows (Scheme 1). Fluoride anion $\left(\mathrm{F}^{-}\right)$adds to TMSCN to give $\mathbf{1} 1$ reacts with the aldehyde for formation of 2 that eliminates $\mathrm{F}^{-}$to produce 3 .

A very effective catalytic system for silylcyanation of various kinds of aldehydes have been developed. The mild experimental conditions, extremely short reaction time, inexpensive catalyst and the wide range of substrate
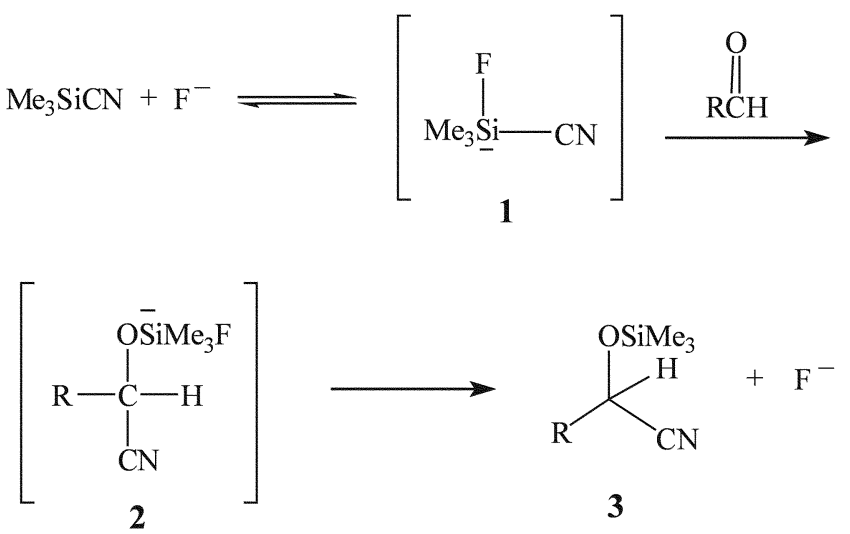

Scheme 1 
Table 2. Trimethylsilylcyanation of Various Aldehydes with KF as Catalyst

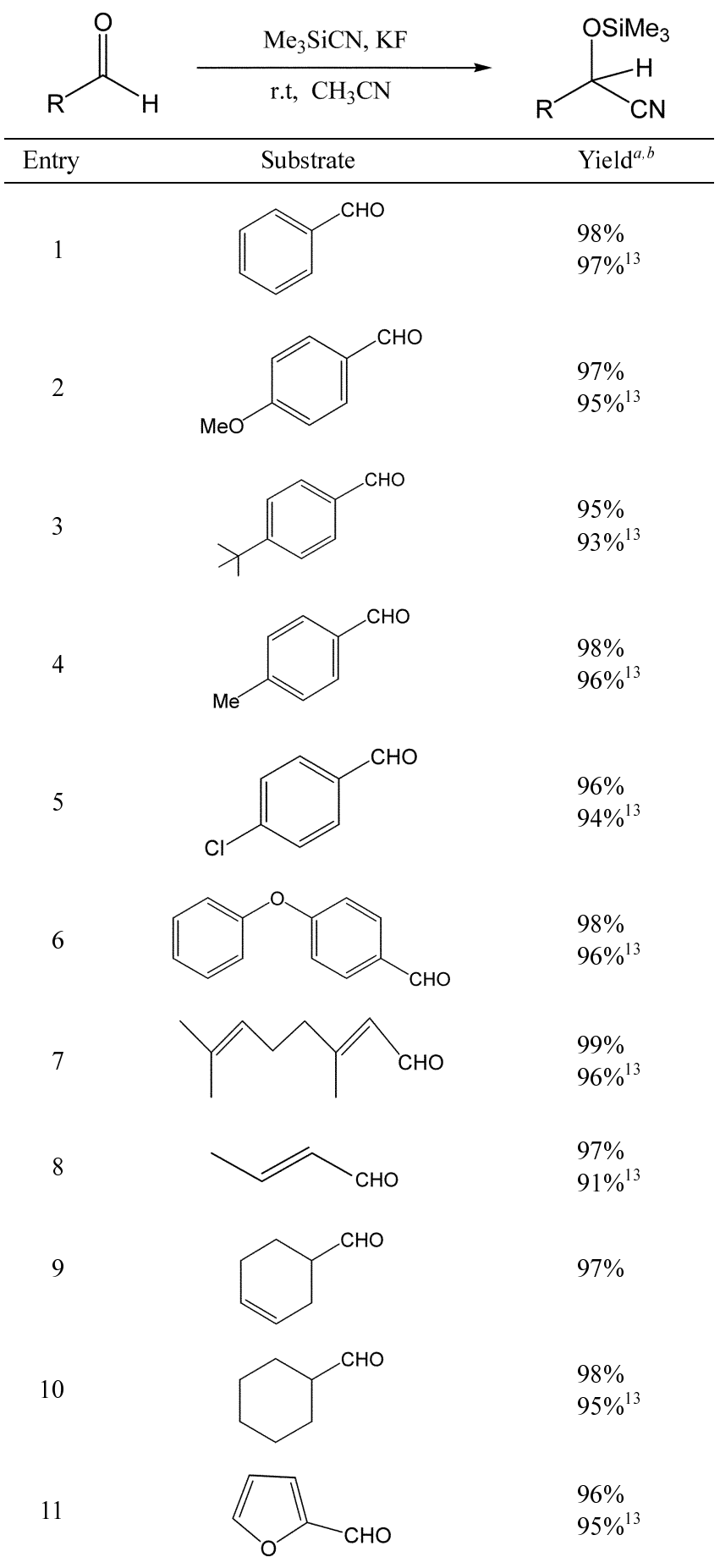

${ }^{a}$ Isolated yield. ${ }^{b}$ Solvent is $\mathrm{CH}_{3} \mathrm{CN}$ and the reaction time was within 20 $\mathrm{min}$. The stoichiometry of the reaction is as follows, $\mathrm{RCHO}(10 \mathrm{mmol})$, $\mathrm{Me}_{3} \mathrm{SiCN}(15 \mathrm{mmol}), \mathrm{KF}(0.2 \mathrm{mmol}), \mathrm{CH}_{3} \mathrm{CN}(10 \mathrm{~mL})$. applicability represent the notable features of this procedure. Although variety of catalysts are known $\mathrm{KF}$ retains great potential for this reactions in terms of yield and reaction time.

\section{Experimental Section}

Silylcyanation of the Aldehydes. Aldehyde (10 mmol), TMSCN (15 mmol) and KF $(0.2 \mathrm{mmol})$ were dissolved in 10 $\mathrm{mL} \mathrm{CH}_{3} \mathrm{CN}$ and reacted for $20 \mathrm{~min}$. The reaction mixture was dried to dryness with rotary evaporator. To this dried mixture $25 \mathrm{~mL}$ of $\mathrm{H}_{2} \mathrm{O}$ was added which was extracted with $60 \mathrm{~mL}$ of $\mathrm{CH}_{2} \mathrm{Cl}_{2}$ four times. $\mathrm{CH}_{2} \mathrm{Cl}_{2}$ solution was dried on $\mathrm{MgSO}_{4}$ and distilled on vacuum. This was on silica gel chromatography (hexane : ethyl acetate $=9: 1$ ) to give the pure sample. ${ }^{1} \mathrm{H}$ and ${ }^{13} \mathrm{C} \mathrm{NMR}$ and HRMS were taken for the purified samples.

Acknowledgement. The authors warmly thank Korea Science and Engineering Foundation for the financial support (R01-2001-00057).

\section{References}

1. Gregory, R. J. H. Chem. Rev. 1999, 99, 3649.

2. Whitesell, J. K.; Apodaca, R. Tetrahedron Lett. 1996, 37, 2525.

3. Saravanan, P.; Vijaya, R.; Singh, V. K. Tetrahedron Lett. 1998, 39, 3823.

4. Jenner, G. Tetrahedron Lett. 1999, 40, 491.

5. Curini, M.; Epifan, F.; Marcotullio, M. C.; Rosati, O.; Rossi, M. Synlett 1999, 315

6. (a) Bandini, M.; Cozzi, P. G.; Melchiorre, P.; Umani-Roncohi, A Tetrahedron Lett. 2001, 42, 3041. (b) Bandini, M.; Cozzi, P. G.; Garelli, A.; Melchiorre, P.; Umani-Ronchi, A. Eur. J. Org. Chem. 2002, 3243.

7. (a) Shen, Y.; Feng, X.; Li, Y.; Zhang, G.; Jiang, Y. Synlett 2002, 793. (b) Chen, F.; Feng, X.; Qin, B.; Zhang, G.; Jiang, Y. Synlett 2003, 558. (c) Shen, Y.; Feng, X.; Li, Y.; Zhang, G.; Jiang, Y. Tetrahedron 2003, 59, 5667.

8. (a) Pan, W.; Feng, X.; Gong, L.; Hu, W.; Li, Z.; Mi, A.; Jiang, Y. Synlett 1996, 337. (b) Jiang, Y.; Gong, L.; Feng, X.; Hu, W.; Pan, W.; Li, Z.; Mi, A. Tetrahedron 1997, 53, 14327.

9. Hamashima, Y.; Sawada, D.; Kanai, M.; Shibasaki, M. J. Am. Chem. Soc. 1999, 121, 2641.

10. Belokon, Y. N.; Caveda-Cepas, S.; Green, B.; Ikonnikov, N. S.; Khrustalev, V. N.; Larichev, V. S.; Moscalenko, M. A.; North, M.; Orizu, C.; Tararov, V. I.; Tasinazzo, M.; Timofeeva, G. I.; Yashikina, L.V. J. Am. Chem. Soc. 1999, 121, 3968.

11. Belokon, Y. N.; North, M.; Parsons, T. Org. Lett. 2000, 2, 1617.

12. Higuchi, K.; Onaka, M.; Izumi, Y. Bull. Chem. Soc. Jpn. 1993, 66, 2016.

13. Kim, S. S.; Lee, J. T.; Song, D. H.; Lee, I. M.; Park, S. Y. Bull. Korean Chem. Soc. 2005, 36, 265. 